\title{
Fostering Virtual Reality Environments to Advance Construction and Engineering Students' Interpersonal Skills
}

\section{Mr. Piyush Pradhananga,}

Piyush Pradhananga is a Ph.D. student in Civil and Environmental Engineering at Florida International University (FIU). Piyush holds a B.S. in Civil Engineering from Tribhuwan University (TU). Following his graduation in 2016, he joined a leading real estate corporation in Nepal as the site engineer working on a multi-million project. He later joined a research firm based in London where he worked as an Engineering Graduate Researcher. Piyush is currently a Graduate Research Assistant at the Moss School of Construction, Sustainability, and Infrastructure at FIU where he focuses on multidisciplinary research that harmonizes sustainability in construction. His other research interests include Sustainable Construction, Construction Safety, Engineering Education, Green Building, and Energy Efficiency Measures.

\section{Dr. MOHAMED ELZOMOR, Florida International University}

Dr. Mohamed ElZomor is an Assistant Professor at Florida International University (FIU), College of Engineering and Computing and teaches at the Moss School of Construction, Infrastructure and Sustainability. Dr. ElZomor completed his doctorate at Arizona State University (ASU), Ira A. Fulton Schools of Engineering. Prior to attending ASU, Dr. ElZomor received a master's of science degree in Architecture from University of Arizona, a master's degree in Engineering and a bachelor of science in Construction Engineering from American University in Cairo. Dr. ElZomor moved to FIU from State University of New York, where he was an Assistant Professor at the college of Environmental Science and Forestry. Mohamed's work focuses on Sustainability of the Built Environment, Engineering Education, Construction Engineering, Energy Efficiency Measures and Modeling, Project Management, and Infrastructure Resilience. Dr. ElZomor has extensive professional project management experience as well as a diverse cross-disciplinary academic knowledge. Mohamed, distinct expertise supports fostering interdisciplinary research in addition to embracing innovative pedagogical approaches in STEM education. Dr. ElZomor has been integrating innovative and novel educational paradigms in STEM education to support student engagement, retention, and diversity.

\section{Ms. Gabriella Santi}

Gabriella Santi grew up in Caracas, Venezuela, where she pursued her Bachelor's of Science in Civil Engineering at the Universidad Metropolitana. After graduating, she worked for two years in a construction company where she was involved in various residential and infrastructure projects. As her interests shifted towards construction management, she then moved to Miami, Florida to pursue a master's degree in the Construction Management program at Florida International University. During her Master's program, she worked as a Graduate Research Assistant at Moss School of Construction Management, researching various topics related to sustainability in third world countries, robotic implementation in the construction industry and aiding STEM majors to improve their professional skills.

\section{Dr. Lu Zhang, Florida International University}

Dr. Lu Zhang is an Assistant Professor in the Moss School of Construction, Infrastructure and Sustainability at Florida International University. She earned her Ph.D. in Civil Engineering with a specialization in Construction Management from the University of Illinois at Urbana-Champaign. She holds a Master of Engineering degree in Construction Engineering and Management from the University of Michigan, and a bachelor's degree in Construction Management from Tongji University, China. Dr. Zhang's research interests include human-building interactions, human-centered value analysis, smart buildings and cities, resilient infrastructure systems, building and civil information modeling, and semantic information modeling. Her research work is funded by multiple agencies, including National Science Foundation, U.S. Department of Transportation, Florida Department of Transportation, Accelerated Bridge ConstructionUniversity Transportation Center, Engineering Information Foundation, and Natural Hazards Center. 


\title{
Fostering Virtual Reality Environments to Advance Construction and Engineering Students' Interpersonal Skills
}

\begin{abstract}
From providing access to clean water to managing large-scale infrastructure projects, the grand challenges that construction managers face in the modern world are equally technical and professional. To overcome these challenges, such aspiring professionals must not only become experts on the technical aspects of their specific field but also develop their soft skills to enable leveraging their technical knowledge in an evolving, increasingly complex and globalized work environment. However, these skills have become stifled, as the typical construction management (CM) graduate spends approximately four years building her/his technical expertise, with little to no time devoted to communication training. For this reason, this research seeks to integrate an objective communication activity in CM curricula that make up for this gap. This research has proven to advance CM students' formal communication skills by creating an engaging educational environment through Virtual Reality (VR) presentation simulations. An initial benchmark survey was administered to 327 STEM students at a minority serving institution, to understand the impact of students' sociodemographics on their presentation skills. Then, a pilot study was offered to $60 \mathrm{CM}$ students, in which they were required to participate in VR Presentation Simulation Trainings. To analyze students' presentation skills improvement through the VR-activity, the authors conducted peer evaluations for pre and post-activity presentations. Additionally, after the VR activity, the authors conducted an exit survey, obtaining the students' perception of the activity. The data obtained from the different surveys and evaluations allowed the authors to (1) develop an ordered probit regression model to understand the influence of several factors such as academic level, gender, first-generation and international status; (2) identify the major deficiencies in CM students' communication and presentation skills; and (3) assess the effects of VR-based presentation simulations on CM students' presentation skills. The results provide valuable feedback and insight into the implementation of alternative learning pedagogies that integrate students' development skills in addition to technical contents.
\end{abstract}

\section{BACKGROUND AND MOTIVATION}

The growing challenges and increasing complexity of today's construction projects demand construction managers that are more competent and capable. Thus, CM professionals must seek to master various skills that expand beyond the technical aspects[1]. Especially in this new era of technology and information, where competition is at an all-time high and technical skills are rapidly becoming a commodity that can be obtained anywhere[2],[3]. One primary soft skill that is crucial for CM professionals to compete and succeed is the ability to communicate and interact effectively[4],[5]. Since Construction managers spend most of their professional life leading and communicating with workforce, developing interpersonal skills and being able to express their ideas effectively is very significant [6]. Such professionals must be capable to seamlessly understand their peers, clients, and stakeholders and vice versa [7],[8].

The lack of soft skills in CM professionals is a known and ongoing issue, as evidence from the construction industry suggests that fresh graduates are constantly challenged by the lack of basic communication skills needed to "hit the ground running." [9],[10]. Moreover, while evidence suggests that communication skills are critical to CM practices, other studies report that these skills are being inadequately developed in educational courses and curricula 
nationwide [6]. The engineering education, therefore, has to effectively add value beyond just teaching technical skills [1],[3]. For instance, although communications have recently been incorporated into engineering schools (motivated by ABET and other accreditations), some universities simply attempt to provide extracurricular skill training to develop students' professional skills [11]. Such initiatives are usually kept separate from the technical curriculum; moreover, most of the CM coursework is heavily skewed towards writing, which ultimately hinders active engagement and communication skills [4]. While teaching $\mathrm{CM}$ students how the physical world works are at the core of their education today, re-examining how institutions teach other fundamentals skills to succeed is needed [12].

Thus, to prepare successful and competent construction managers, CM education must adapt and shift to more innovative learning techniques that allow aspiring CM professionals to grow professionally. For this reason, this paper developed an ordered probit regression model to understand the influence of factors such as academic level, gender, first-generation and international status; (2) identify the major deficiencies in CM students' communication and presentation skills; and (3) assess the effects of VR-based presentation simulations on CM students' presentation skills. Additionally, the research results provide valuable feedback and insight into the implementation of alternative learning pedagogies that integrate students' development skills in lieu of technical contents.

\section{METHODOLOGY}

A benchmark survey was administered to 327 STEM students at a minority serving institution, as shown in Figure 1. Based on this survey, a pilot study was conducted in five $\mathrm{CM}$ courses including a total of 60 students. In this pilot study, students were required to participate in a VR Presentation Simulation Training, in which underrepresented students were immersed in semi-realistic environments. Peer-evaluations were obtained within two of the courses involved, to measure the training's effectiveness. Finally, an exit survey was held to obtain the students' feedback about the virtual training.

\begin{tabular}{|c|c|c|c|}
\hline $\begin{array}{c}\text { Benchmark Survey } \\
\text { administered to } 327 \text { STEM } \\
\text { students at a minority-serving } \\
\text { institution }\end{array}$ & $\begin{array}{l}\text { Pilot Study: } 60 \text { students take } \\
\text { part in a VR-Presentation } \\
\text { Simulation Activity }\end{array}$ & $\begin{array}{c}32 \text { students involved in this } \\
\text { pilot study obtained pre-VR } \\
\text { and post-VR activity } \\
\text { evaluations }\end{array}$ & $\begin{array}{l}\text { An exit survey was } \\
\text { administered to the students } \\
\text { involved in the pilot study }\end{array}$ \\
\hline $\begin{array}{l}\text { Identified the relationship } \\
\text { between students' current } \\
\text { skills and their } \\
\text { socio-demographic profiles }\end{array}$ & $\begin{array}{l}\text { Semi-realistic virtual } \\
\text { presentation simulation } \\
\text { sessions were offered, to } \\
\text { nurture the students } \\
\text { presentation skills. Skills } \\
\text { such as eye contact were } \\
\text { analyzed within the } \\
\text { software. }\end{array}$ & $\begin{array}{l}\text { Paired T-Test analysis } \\
\text { and boxplots in Rstudio } \\
\text { were developed to } \\
\text { assess the impact of the } \\
\text { VR activity on the } \\
\text { students' skills were } \\
\text { analyzed. }\end{array}$ & $\begin{array}{l}\text { Obtained relevant feedback } \\
\text { into the VR training }\end{array}$ \\
\hline
\end{tabular}

Figure 1. Research Overview

First, a benchmark survey was administered to 327 STEM students at a minority-serving institution. Through this survey, the students self-evaluated their strengths and weaknesses, as well as provided their socio-demographic profiles. Following the benchmark survey, a pilot study targeted five construction management courses to provide targeted communication trainings that would effectively stimulate student development. In this pilot study, students in the five courses participated in VR Presentation Simulation Trainings as part of the courses' syllabi, as shown in Figure 2. The VR Simulations were conducted through Virtual Orator, a presentation simulation software, that allows the minority students to be immersed in various semi-realistic environments and rehearse in front of realistic and interactive audiences. 


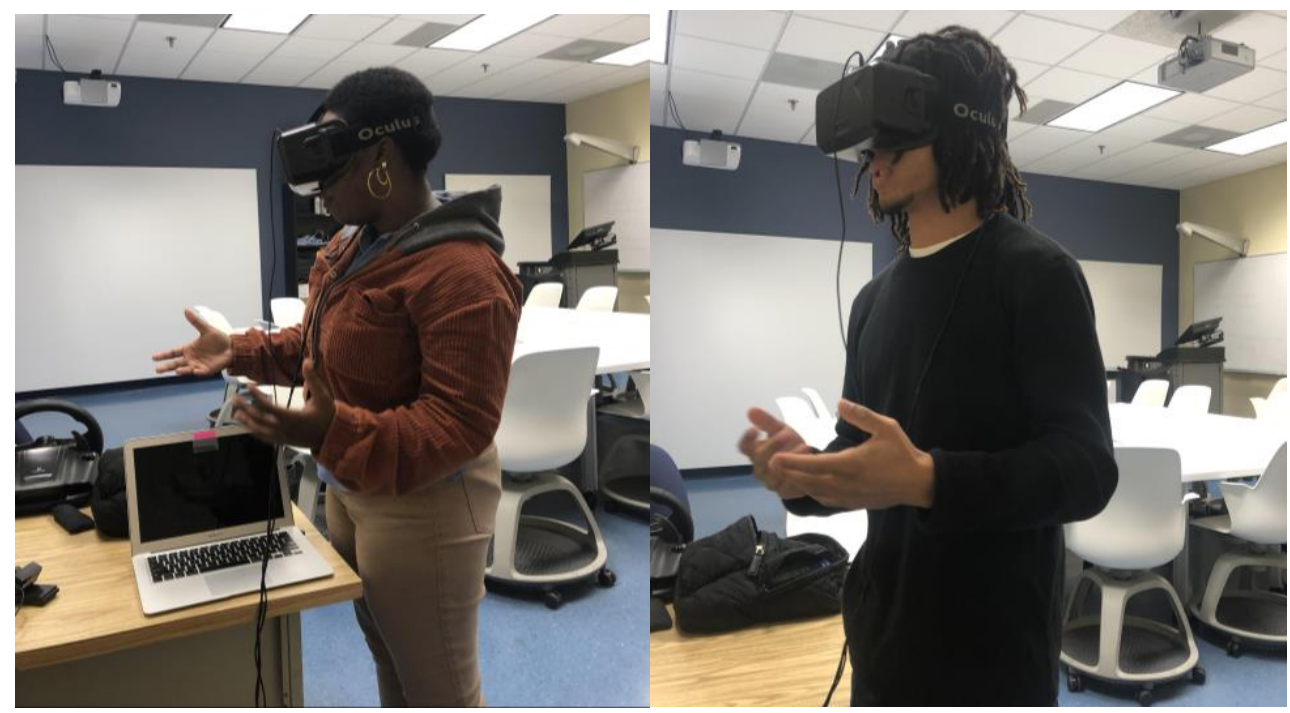

Figure 2. Students in the VR Presentation Simulation Sessions

The software also provides valuable feedback, such as the percentage of time spent with appropriate or inappropriate eye contact, length of presentation, and length of presentation slides. Additionally, the software allows users to personalize each session by indicating the type of audience desired, the level of attention of the audience throughout the simulation, and level of noise/disturbance within the audience, among others (see Figure 3). During the training, students uploaded their presentation slides and practiced their presentation performance in different semi-realistic presentation environments. Students were required to choose a specific environment, such as a hotel conference room, a theatre, small to large classrooms, business meeting rooms, and the different criteria, thus obtaining personalized sessions for each student, as shown in Figure 3.

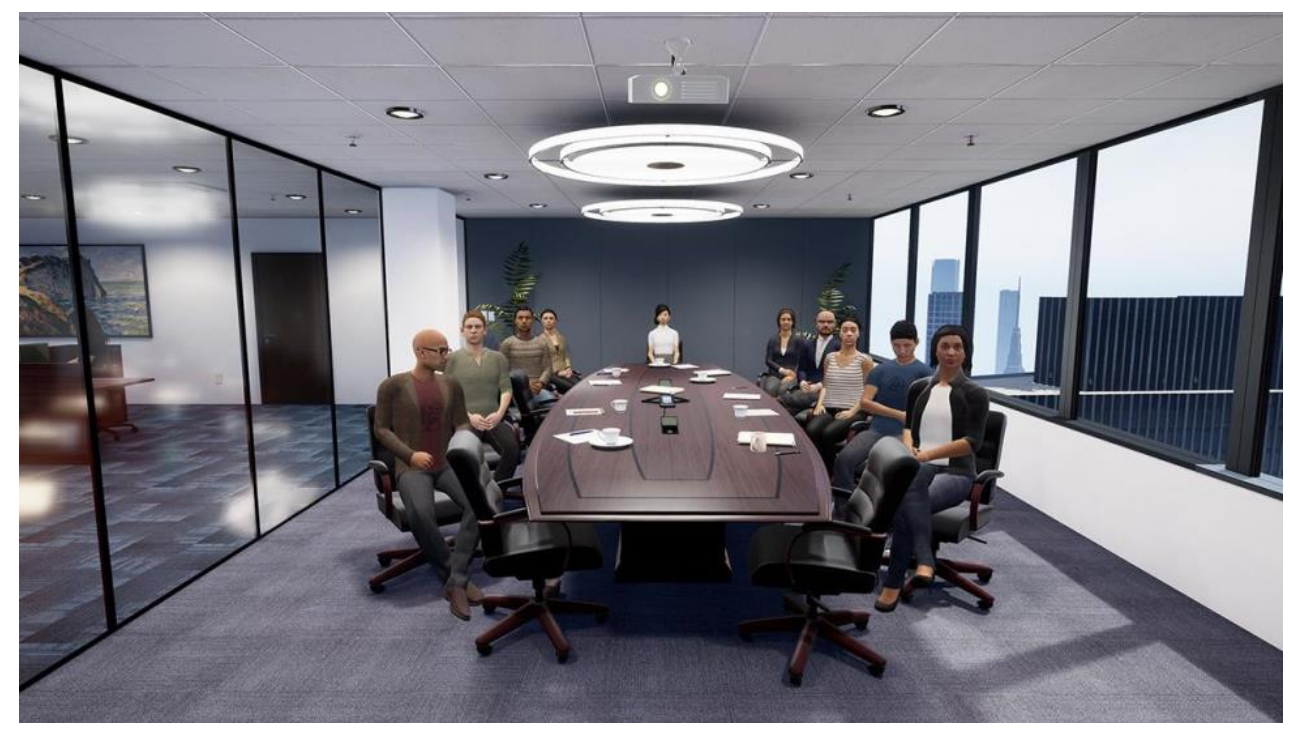

Figure 3. Model of a Business meeting room Setting in Virtual Orator

Out of the five courses involved in this pilot study, two courses (Sustainable Construction, and A Sustainable Approach to Construction) participated in pre and post-simulation presentations. Each student was peer-evaluated for each presentation based on the criteria stated in Figure 4. Peer-evaluations were chosen as a measure, as it is an effective quality assurance measure in many contexts, including science, business, and education, and is considered more extensive than other common evaluation mediums [14],[15]. Peer- 
evaluations have been shown to provide many advantages in STEM, including getting students to think about the exercise more deeply and seriously, and recognizing others' viewpoints and criticism [1]. By conducting an ordered probit analysis, the authors were able to analyze the relationship between students' current presentation skills and factors such as academic level, gender, first-generation and international status which were obtained from the course survey. An ordered probit regression analysis is the selected method for the collected data, as this analysis is fit for the generalization of cases of more than two outcomes of an ordinal dependent variable (a variable with potential values such as poor, fair, good, excellent) [13]. Through this analysis, the authors determined which independent variable had a statistically significant effect on the dependent variable, as well to determine how well the model predicts it. For this model, the dependent variable was defined as Students' Current Skills, while the independent variables are Gender, Academic Level, International Status, Previous Communication Skills Training, Public Speaking Experience, First Generations, and Interest on Communication Training. The ordinal probit regression model utilizes these parameters through the following equation:

$$
y_{i}^{*}=X_{i} \beta+\varepsilon
$$

Where $y_{i}{ }^{*}$ is a latent variable measuring the professional development of the ith participant; $X_{i}$ is a ( $\left.\mathrm{k} \mathrm{x} 1\right)$ vector of observed nonrandom explanatory variables; $\beta$ is a $(\mathrm{k} \mathrm{x} 1)$ vector of unknown parameters, and; error factor $(\varepsilon)$ captures the reality that the Student Skills is not perfectly predicted by the regression equation. Therefore, Student Skills, $y_{i}$ is determined from the model as follows:

$$
y_{i}=\left\{\begin{array}{c}
1 \text { if }-\infty \leq y_{i}{ }^{*} \leq \mu_{1} \quad \text { (Extremely poor presentation skills) } \\
2 \text { if } \mu_{1} \leq y_{i}{ }^{*} \leq \mu_{2} \quad \text { (Poor presentation skills) } \\
3 \text { if } \mu_{2} \leq y_{i}{ }^{*} \leq \mu_{3} \quad(\text { Average presentation skills) } \\
4 \text { if } \mu_{3} \leq y_{i}{ }^{*} \leq \mu_{4} \text { (Good presentation skills) } \\
5 \text { if } \mu_{4} \leq y_{i}{ }^{*} \leq \mu_{5} \text { (Excellent presentation skills) }
\end{array}\right.
$$

In equation 2 , the partial change in $y^{*}$ with respect to $X_{i}$ is $\beta_{\mathrm{i}}$ units. This implies that for a unit change in $X_{i}, y^{*}$ is expected to change by $\beta_{i}$ units, holding all variables constant.

Furthermore, the significance test uses the t-score to describe how the mean of the data sample with a certain number of observations is expected to behave. On the other hand, the Pvalue indicates the confidence level, in terms of correlation, of each variable to the dependent variable. The confidence interval in the analysis is assumed to be $90 \%$ for this study; thus, the area under the curve $(\mathrm{z})$ is obtained as 1.645 .

The results from both pre and post VR peer-evaluations were also analyzed using paired t-test to determine the mean difference between two evaluation. A paired t-test is a parametric test in which assumptions are made about parameters of a distributed population from which a sample is drawn. Through this analysis, the authors analyzed the mean difference between the two data sets. For this paired t-test analysis, a confidence interval of $95 \%$ is set. Then, the result of paired t-test was also graphically represented using box plots with line plots which provides the correlation of the students' improvement throughout the VR-Activity. 


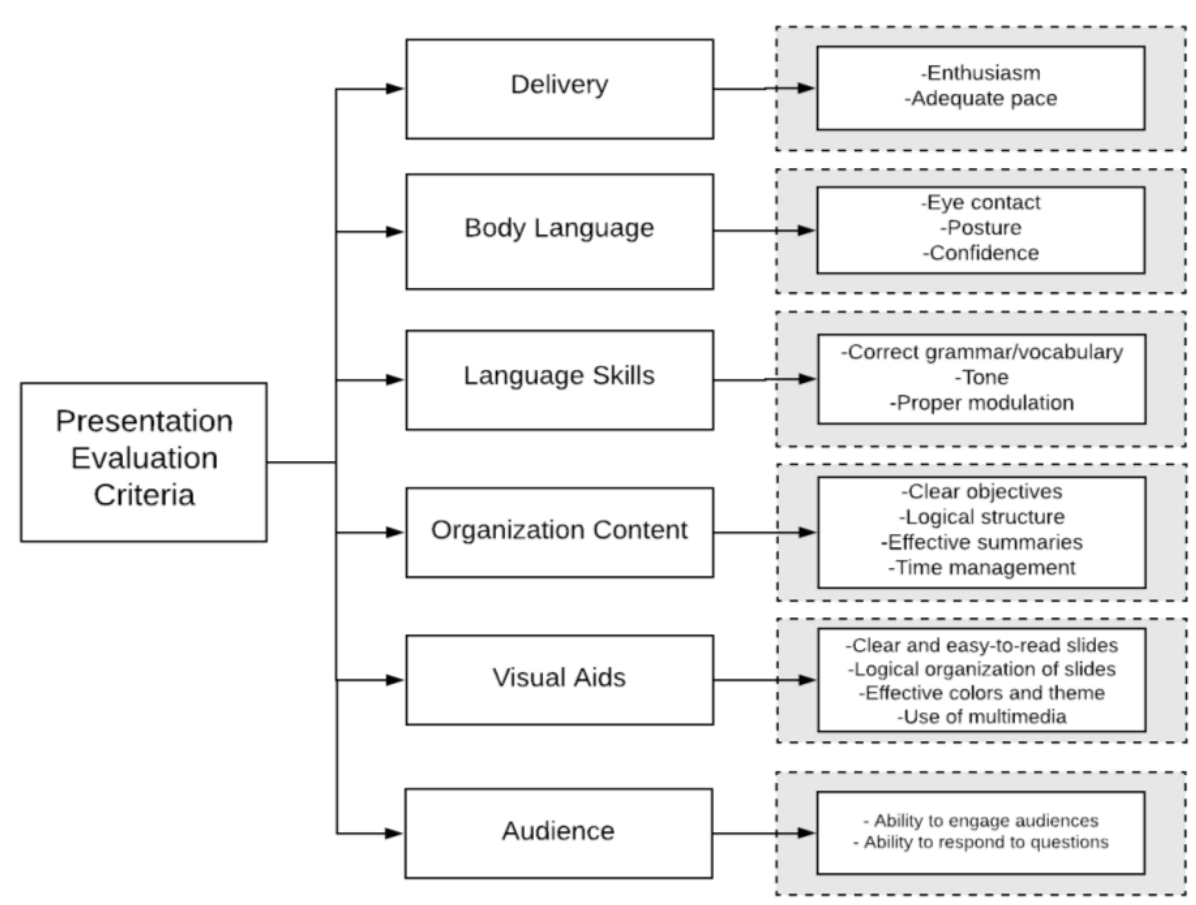

Figure 4. Flowchart explaining the Presentation Evaluation Criteria

Furthermore, results from the VR sessions allowed the authors to identify the students' main weaknesses, as well as provided relevant insight into their presentation delivery.

Additionally, students from all five courses provided their feedback to the activity through an exit survey. In this survey, students rated their activities according to their perception about the effectiveness of each activity, as well as indicate which specific skills improved the training skills and the overall highlights/comments.

\section{RESULTS AND DISCUSSIONS}

The proposed activity created an engaging educational environment seeking to enhance students' communication and presentation skills, thus honing their professional development. Their participation in the study increased their confidence, improved their performance and engagement, and allowed them to develop sufficient skills to convey technical information to diverse audiences. The data obtained from the benchmark survey allowed the authors to understand the impact of students' socio-demographics on their current skills. Meanwhile, the data obtained from the peer-evaluations allowed the authors to evaluate the activity's impact, identify the students' strengths and weaknesses, and evaluate their professional development and growth.

To analyze the relationship between students' presentation skills and socio-demographic profiles, an ordered probit analysis was developed. This method was selected since it provides an appropriate fit to the data obtained. Table 1 provides the estimated results of the student skills with a Pseudo $\mathrm{R}_{2}$ value of 0.55 . The regression coefficient values of Gender, Academic Level, International Status, Previous Communication Skills Training, Public Speaking Experience, First Generations, and Interest on Communication Training are 0.003, $0.038,0.044,0.002,0.027,0.006$, and 0.062, respectively. Since the P-value for all the factors are significant, it can be inferred that students' presentation skills are highly influenced by their socio-demographic profile. Therefore, the statistical analysis results in Table 1 suggests: 
1. STEM students interested in communication skills training are more likely to achieve higher presentation skills than those who are not interested, as they are more motivated to place more effort in ameliorating their presentation performance.

2. International STEM students are more likely to possess higher presentation skills. This could be since internationals must overcome multiple barriers when studying abroad; thus, they tend to put more effort into improving their overall skills.

3. Regarding gender, male STEM students tend to possess higher presentation skills. This could be since STEM is a male-dominated industry; thus, male individuals could be more pressured to stand out and be more competitive.

4. First-generation STEM students are less likely to have their presentation skills developed. This could be since first-generation students potentially face additional barriers than their counterparts, when in higher education programs. Additionally, these students have been shown to have less family influence to develop these soft skills outside their academic settings [16]. That said, and since first-generation students need more training, higher education should focus on fostering such trainings to this student body to support their success in STEM.

5. STEM graduate students are more likely to possess higher communication skills, possibly since graduate students maintain more academic knowledge, experience, and different exposures than undergraduates. Thus, this could indicate that undergraduate programs require reinforcement through additional training specifically in the communication/presentation areas.

6. Students who have had previous communication skill training or public speaking experience are more likely to have better presentation skills. This could indicate that offering students different training activities and opportunities to practice their skills can, in fact, help further develop their presentation and communication abilities.

Regardless of their current skills, all STEM students, specifically women and first-generation students, benefit greatly from innovative communication skills activities that can successfully foster students' growth.

Table 1. Coefficients and P-Value from Ordered Probit Analysis

\begin{tabular}{|c|c|c|c|c|}
\hline Variables & $\begin{array}{c}\text { Coeff } \\
(\beta)\end{array}$ & $\begin{array}{l}\text { Std. } \\
\text { Error }\end{array}$ & $\mathrm{Z}$ & P-Value \\
\hline $\begin{array}{l}\text { 1. Indicator variable for Interest on Communication } \\
\text { Training } \\
\text { (1 if respondents are interested, } 0 \text { otherwise) }\end{array}$ & 1.537 & 0.82 & 1.87 & 0.062 \\
\hline $\begin{array}{l}\text { 2. Indicator variable for International Status } \\
\text { (1 if respondents are International, } 0 \text { otherwise) }\end{array}$ & 2.36 & 1.17 & 2.01 & 0.044 \\
\hline $\begin{array}{l}\text { 3. Indicator variable for Gender } \\
\text { ( } 1 \text { if respondents are female, } 0 \text { otherwise) }\end{array}$ & -2.95 & 0.9 & -2.98 & 0.003 \\
\hline $\begin{array}{l}4 . \text { Indicator variable for First-Generation } \\
\text { (1 if respondents are first generation students, } 0 \text { otherwise) }\end{array}$ & -4.48 & 1.62 & -2.76 & 0.006 \\
\hline $\begin{array}{l}\text { 5. Indicator variable for Degree } \\
\text { (1 if respondents are undergraduate, } 0 \text { otherwise) }\end{array}$ & -1.55 & 0.74 & -2.08 & 0.038 \\
\hline $\begin{array}{l}\text { 6. Indicator variable for Previous Communication } \\
\text { Training } \\
\text { (1 if respondents are not previously trained, } 0 \text { otherwise) }\end{array}$ & -4.18 & 1.33 & -3.13 & 0.002 \\
\hline $\begin{array}{l}\text { 6. Indicator variable for Public Speaking Experience } \\
\text { (1 if respondents are not experienced, } 0 \text { otherwise) }\end{array}$ & -1.75 & 0.79 & -2.21 & 0.027 \\
\hline $\boldsymbol{\mu}_{1}$ & -6.8 & 1.82 & & \\
\hline $\boldsymbol{\mu}_{2}$ & -3.8 & 1.24 & & \\
\hline$\mu_{3}$ & 1.7 & 1.17 & & \\
\hline
\end{tabular}


Based on these benchmark results, a pilot study was conducted throughout five different construction management courses. The students within these courses were required to participate in VR Presentation Simulation Trainings. To assess the results of the VR Simulation Training, students from two of the courses involved in the pilot study were involved in pre- and post-activity presentation evaluations. Through a 5-point Likert Scale, where 1 indicated extremely poor skills and 5 indicated excellent skills, the students rated their classmates on their presentation's delivery, body language, language skills, organization and content, visual aids, and ability to engage audiences. Also, a Paired T-test analysis was conducted, as shown in Table 2. Based on these results, it can be concluded that the P-value for all the variables is less than 0.05 , indicating there is a significant difference in the means of the two data sets (i.e. pre-activity results and post-activity results). As shown in Table 2, the mean difference for each variable has a negative sign, indicating that the students did in fact improve their different presentation skills through the VR Training.

Table 2. Paired T-Test

\begin{tabular}{|c|c|c|c|c|c|}
\hline & Mean & Std. Deviation & $\mathrm{t}$ & $\mathrm{df}$ & Sig. \\
\hline Delivery & -.10257 & .23777 & -2.440 & 31 & .017 \\
\hline Body Language & -.13714 & .27375 & -2.834 & 31 & .006 \\
\hline Language Skills & -.23761 & .20632 & -6.515 & 31 & .000 \\
\hline Organization \& Content & -.08939 & .12465 & -4.057 & 31 & .000 \\
\hline Visual Aids & -.15765 & .27165 & -3.283 & 31 & .002 \\
\hline Audience & -.75486 & .66031 & -6.567 & 31 & .000 \\
\hline
\end{tabular}

To graphically represent the results of the paired t-test analysis, boxplots were developed through RStudio, which shows the respondents' development based on the training provided. As shown in Figure 5, the students experienced growth across all the different criteria, including their ability to engage audiences, their body language, and delivery, among others. It is also worth noting that skills such as organization \& content and visual aids did not demonstrate such a significant improvement, as their median is maintained constant throughout the semester. Regardless, the difference in quartiles indicate that many students did in fact, improve their skills in these areas. This indicated that the VR Presentation Simulation training successfully improved the students' presentation skills. Not all the communication skills improved significantly, which means that the undeveloped skills possibly require additional innovative training methods and/or continuous VR-presentation simulation training to observe a major significant change in the students' performances. 

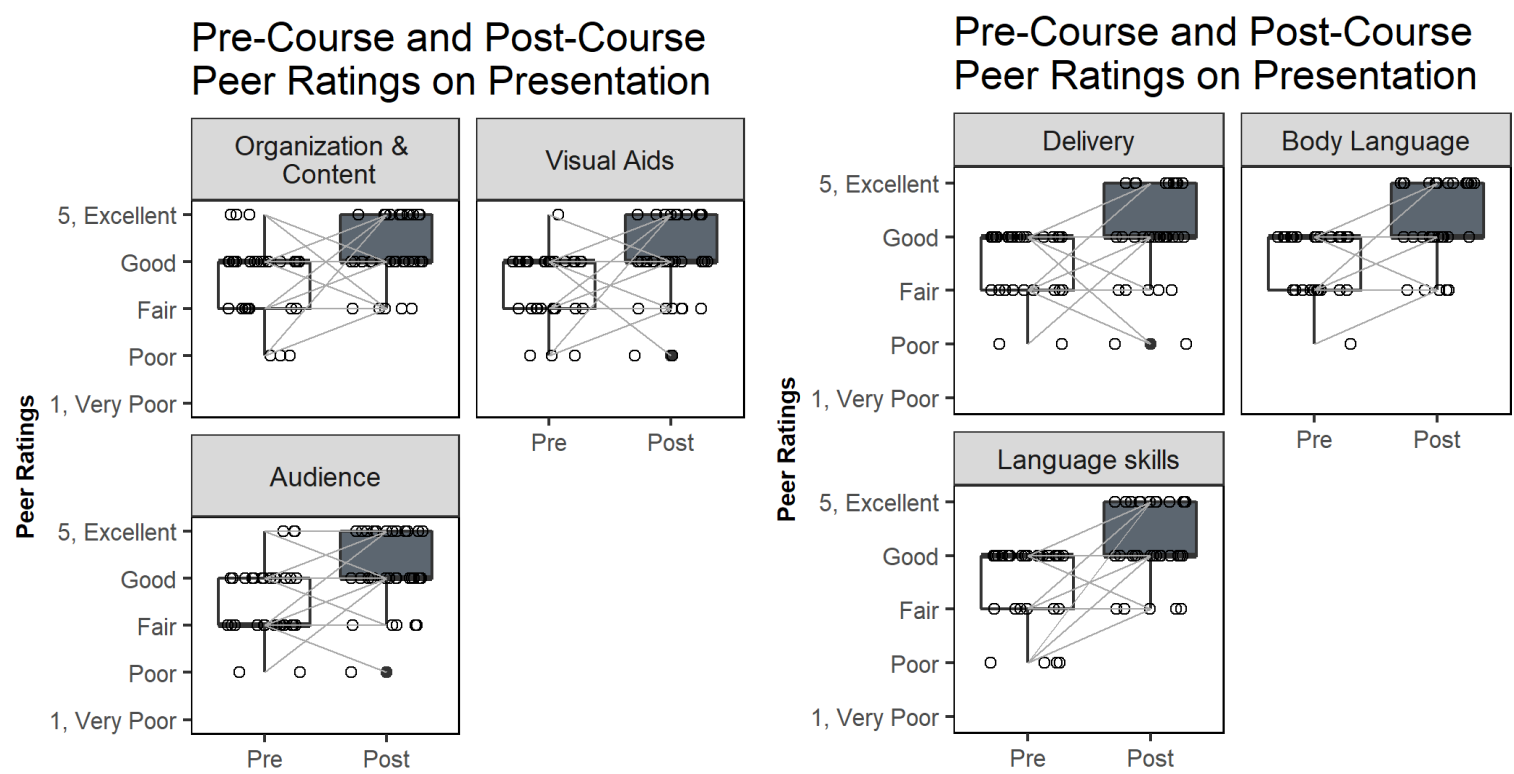

Figure 5. Student Improvement, $\mathrm{N}=32$

Additionally, the obtained feedback from Virtual Orator (VO) was used to analyze specific presentation skills, such as the time spent within each presentation slide, as shown in Figure 6. Moreover, the feedback also analyzes the eye contact during the presentation, indicating the specific eye contact spent with the different regions of the audience, as shown in Figure 7 , and 8 . Based on the results, $91 \%$ of the students demonstrated inappropriate eye contact, as they did not maintain sufficient and balanced contact with the audience. Improvement in eye contact during presentations can significantly increase a speaker's credibility in terms of qualification and effectiveness thus, it is an important aspect to master when communicating with peers [17]. By offering students' specific statistics on their presentation mistakes, minority students may then be advised to rehearse through the VR Simulations and reinforce their weaknesses to improve their communication skills.

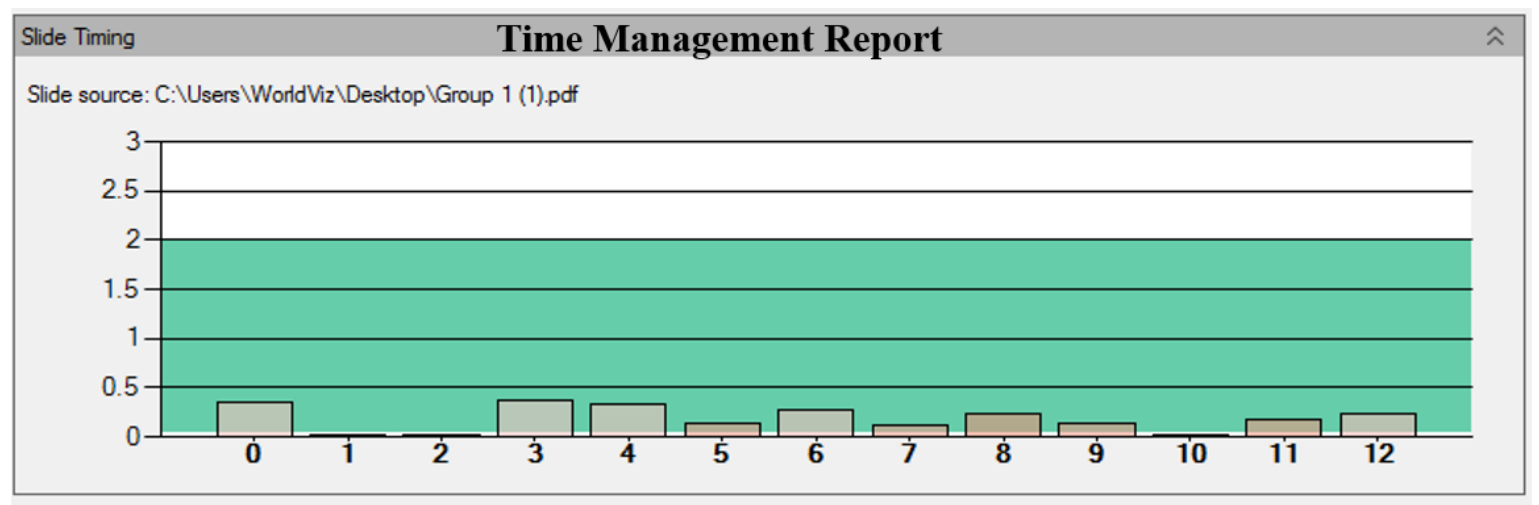

Figure 6. Example of Time Management Output Report 
You looked at:

Audience region 'Left Front': 18 eye contacts for a total of $0 \mathrm{~m}$ 38s; ave. contact length $2 \mathrm{~s}$; shortest contact was $1 \mathrm{~s}$; longest contact was $6 \mathrm{~s}$; longest duration without contact was 49 s.

Audience region 'Right Front': 6 eye contacts for a total of $0 \mathrm{~m}$ 8s; ave. contact length $1 \mathrm{~s}$; shortest contact was $1 \mathrm{~s}$; longest contact was $2 \mathrm{~s}$; longest duration without contact was 65 s.

Audience region 'Left Center': 4 eye contacts for a total of $0 \mathrm{~m} 8 \mathrm{~s}$; ave. contact length $2 \mathrm{~s}$; shortest contact was $1 \mathrm{~s}$; longest contact was $4 \mathrm{~s}$; longest duration without contact was 81 s.

Audience region 'Right Center': 5 eye contacts for a total of $0 \mathrm{~m} 15 \mathrm{~s}$; ave. contact length $3 \mathrm{~s}$; shortest contact was $1 \mathrm{~s}$; longest contact was $7 \mathrm{~s}$; longest duration without contact was $99 \mathrm{~s}$.

Audience region 'Left Back': 2 eye contacts for a total of Om 10s; ave. contact length $5 \mathrm{~s}$; shortest contact was $1 \mathrm{~s}$; longest contact was $9 \mathrm{~s}$; longest duration without contact was 99s.

Audience region 'Right Back': 5 eye contacts for a total of Om 8s; ave. contact length $2 \mathrm{~s}$; shortest contact was $1 \mathrm{~s}$; longest contact was $3 \mathrm{~s}$; longest duration without contact was 108 s.

Figure 7. Example of Eye Contact Output Report

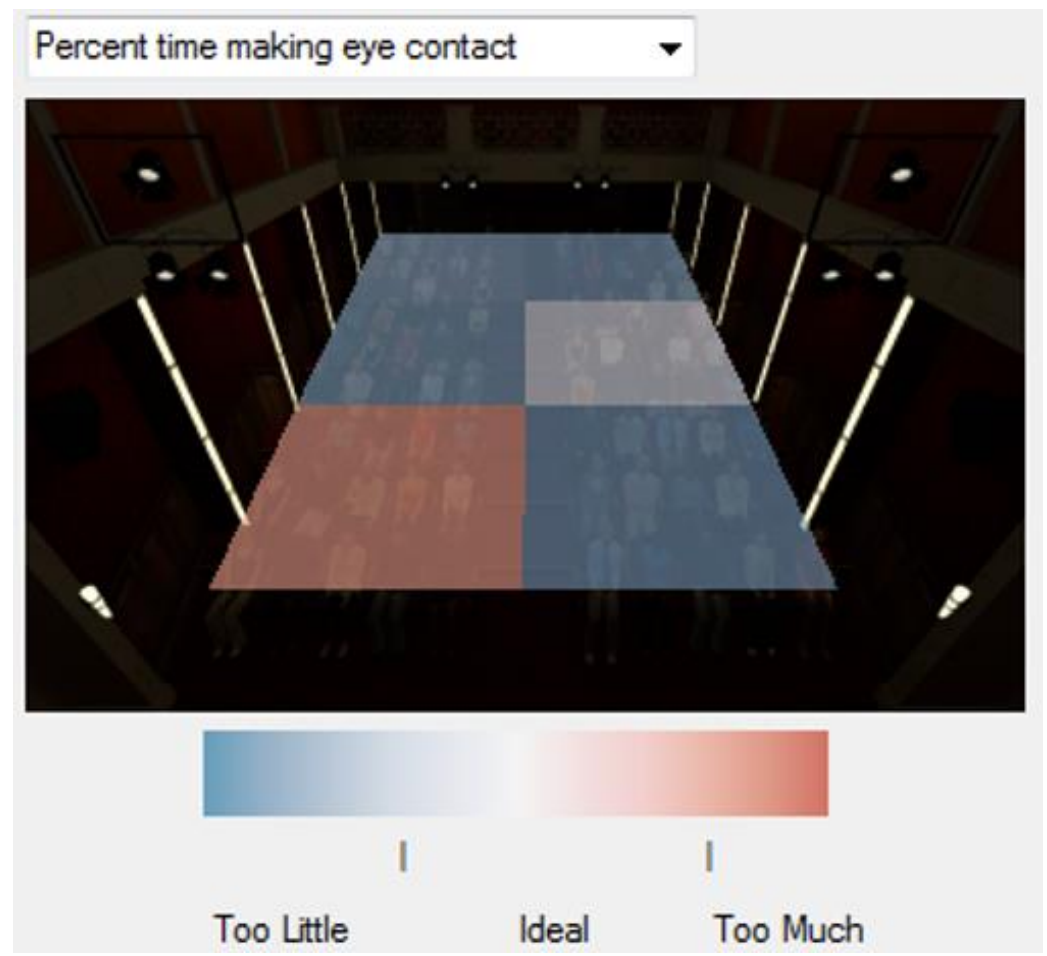

Figure 8. Example of Eye Contact Output Report

Lastly, an exit survey was distributed to 60 students involved in the VR training simulations. In this survey, the students were able to rate their perception of the effectiveness of the VR activity, as well as provide information regarding the skills they noticed improvement, and their highlights and comments. Based on the results, $99 \%$ of the respondents believe communication skills training activities would help STEM (Disciplines in Science, Technology, Engineering, and Mathematics) students' professional development. Additionally, as shown in Figure 9, the vast majority considered the VR presentation simulation trainings to be extremely effective to their professional development, while only $2 \%$ considered the activity as ineffective. 
Student Self-Rating for VR Activity, N=60

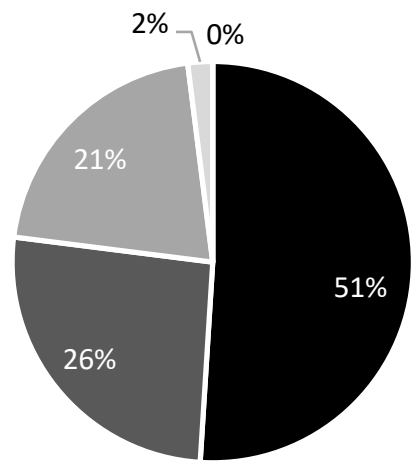

- Extremely Effective

- Higly Effective

- Moderately Effective

- Slightly Effective

Ineffective

Figure 9. Student Self-Rating of VR Activity

Students were also asked to indicate which specific communication skills actually were improved throughout the VR training. As shown in Figure 10, approximately $47 \%$ believed they improve their eye contact (EC), while $42 \%$ believe it enhanced their time management (TM) skills, 35\% their presentation pace (PP), 25\% their posture (P), 21\% their enthusiasm in presentation delivery (EP) and their ability to engage audiences (EA), 19\% their language proficiency (LP) and presentation structure (SP), 16\% their use of multimedia (MM), $6 \%$ their ability to respond appropriately to questions (Q), and 3\% believed this activity did not improve any skills. These results indicate a significant growth throughout the implementation of the VR activity, as $97 \%$ of the students demonstrate and improvement in their skills.

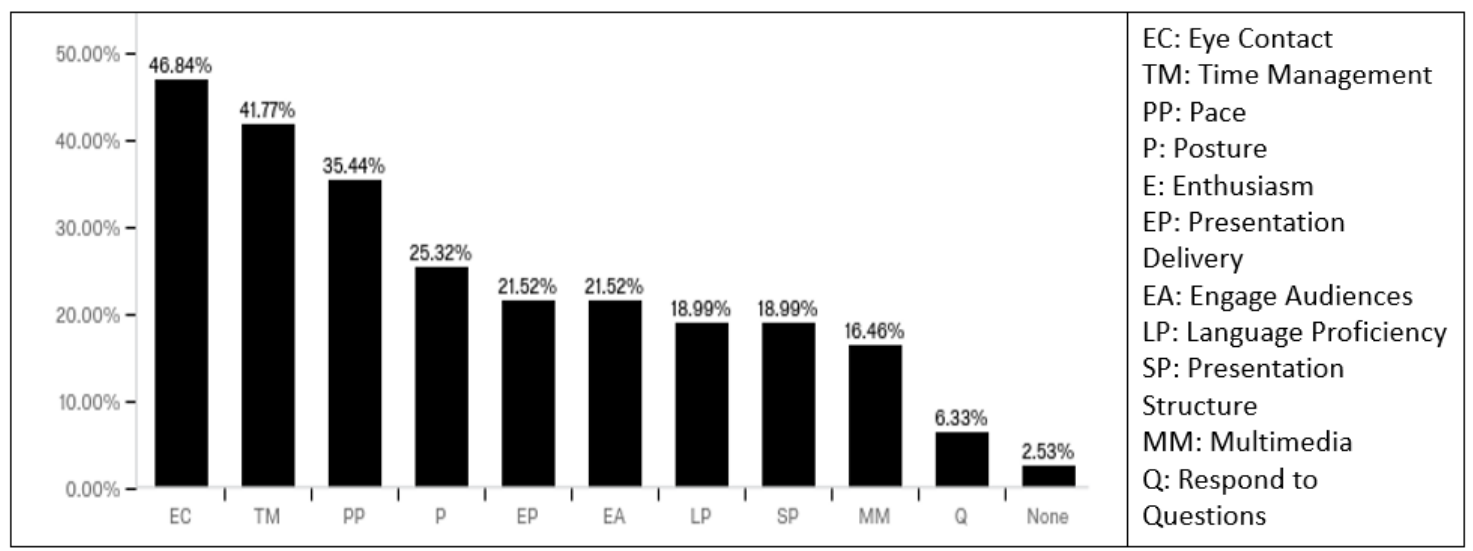

Figure 10. Students' Perception of Improvement of Skills, N=60

Furthermore, $82 \%$ of students indicated they would continue to train their presentation skills through the VR Simulations beyond this pilot study. Thus, offering alternative innovative learning techniques is, in fact, an effective way to develop and nurture students' communication skills.

Finally, the students' feedback about the VR Presentation Simulation Training sessions were obtained. Based on qualitative analysis, $88 \%$ of the students provided positive feedback, as they considered the training "Impressive", " helped boost confidence and maintain eye contact with the audience" and "really helped in terms of pace, nervousness, to be bold, body gesture, ability to pass information to the audience, eye contact, to be time conscious and finally to be able to deliver an important pitch precisely and concisely". On the other hand, 
$22 \%$ of the students did not provide positive feedback to the training, as they expected the software to provide more advanced graphics, as well as not being realistic enough with the audiences being "Avatars". Additionally, some students believed it is an interesting concept, yet the equipment caused some discomfort including minor dizziness.

\section{LIMITATIONS AND FUTURE WORK}

The study assessed the effects of a VR-based presentation simulation training on CM students' presentation performance. However, there were some limitations when conducting the research including: (1) the peer-evaluations conducted within this research may be subjective due to personal opinions and self-judgments; (2) the students' peer-assessment could be influenced by the students' previous communication skills knowledge, despite the fact that the authors believe this knowledge was sufficient to evaluate their peers appropriately; (3) the students' skills improvement throughout the course could be influenced by external factors throughout the course of the semester and not only due to the VR-training implemented, however the authors believe the results reflect and are associated by the influence of the VR training on the students' professional growth. The future stage of this study will conduct social media activities that will further engage and nurture these students' presentation skills.

\section{CONCLUSION}

To become competent engineers and construction managers, STEM students must invest in developing their professional skills, such as communication and presentation skills. Based on the benchmark survey, it is found that female, first generation and undergraduate students are less likely to possess proficient communication skills and thus require targeted training activities to embrace underrepresented student's growth. Additionally, through peerevaluations, results indicate that the main weaknesses that CM students depicted were inability to engage audiences and deliver their presentations with proper body language. A pilot study was implemented in $5 \mathrm{CM}$ courses throughout an academic semester, where students were offered VR-Presentation Simulation Training. Participation in the VR-based presentation simulation training allowed minority students improve all specified presentation skills, specifically improving eye contact, time management, presentation pace, and posture. Overall, students provided positive feedback into this innovative training strategy, as more than $75 \%$ of the students participating in the pilot study rated the VR activity as highly and extremely effective. This study not only focused on integrating innovative presentation training into courses' syllabi to ensure all students are exposed to such training, but also provided relevant feedback and the opportunity to practice these skills during in-class presentations.

\section{ACKNOWLEDGMENTS}

The author was funded by grant AWD000000010067 from the Engineering Information Foundation (EIF) and this support is gratefully acknowledged. The authors also would like to thank the research team, Dr. Zhang, Dr. Pradhananga, and Dr. Kalasapudi, for their support. Any opinions, findings, conclusions, or recommendations expressed in this paper are those of the writers and do not necessarily reflect the views of EIF. 


\section{REFERENCES}

[1] M. Riemer, "English and Communication Skills for the Global Engineer," Glob. J. Eng. Educ., vol. 6, no. 1, pp. 91-100, 2002.

[2] S. Cerri, "EFFECTIVE COMMUNICATION SKILLS FOR ENGINEERS," pp. 625629, 2000.

[3] G. Tryggvason and D. Apelian, "Re-Engineering Engineering Education for the Challenges of the 21st Century," JOM, no. 1, p. 1610, 2006.

[4] T. J. Kennedy and M. R. L. Odell, "Engaging Students In STEM Education," Sci. Educ. Int., vol. 25, no. 3, pp. 246-258, 2014.

[5] Society of Manufacturing Engineers Education Foundation, "Manufacturing Education Plan: Phase 1 Report - Industry Identifies Competency Gaps Among Newly Hired Engineering," 1997.

[6] A. L. Darling and D. P. Dannels, "Practicing engineers talk about the importance of talk: A report on the role of oral communication in the workplace," Commun. Educ., vol. 52, no. 1, pp. 1-16, 2003, doi: 10.1080/03634520302457.

[7] D. F. Whalen et al., "Academic Success for STEM and Non-STEM Majors," J. STEM Educ. Innov. Res., vol. 11, no. 1, pp. 45-60, 2010.

[8] M. ElZomor, M., Mann, C., Doten-Snitker, K., Parrish, K., Chester, "Leveraging Vertically Integrated Courses and Problem-Based Learning to Improve Students' Performance and Skills," J. Prof. Issues Eng. Educ. Pract., vol. 144, no. 4, p. 04018009, 2018, doi: 10.1061/(asce)ei.1943-5541.0000379.

[9] P. SAGEEV and C. ROMANOWSKI, "A Message from Recent Engineering Graduates in the Workplace: Results of a Survey on Technical Communication Skills," no. October, 2001.

[10] A. Keane and I. S. Gibson, "Communication Trends in Engineering Firms: Implications for Undergraduate Engineering Courses," Int. J. Eng. Educ., vol. 15, no. 2, pp. 115-121, 1999.

[11] J. V. Farr and B. A. Bowman, "Abet accreditation of engineering management programs: Contemporary and future issues," EMJ - Eng. Manag. J., vol. 11, no. 4, pp. 7-13, 1999, doi: 10.1080/10429247.1999.11415044.

[12] M. Elzomor and O. Youssef, "Coupling Haptic Learning with Technology To Advance Informal STEM Pedagogies," Am. Soc. Eng. Educ.

[13] Stata.com, "Ologit — Ordered logistic regression."

[14] D. Kumrow and B. Dahlen, "Is Peer Review an Effective Approach for Evaluating Teachers?," Clear. House A J. Educ. Strateg. Issues Ideas, vol. 75, no. 5, pp. 238-241, 2002, doi: 10.1080/00098650209603947.

[15] C. Bauer, K. Figl, M. Derntl, P. P. Beran, and S. Kabicher, "The student view on online peer reviews," Proc. Conf. Integr. Technol. into Comput. Sci. Educ. ITiCSE, pp. 26-30, 2009, doi: 10.1145/1562877.1562892.

[16] H. London, "Transformations: Cultural Challenges Faced by First-Generation Students," New Dir. Community Coll., vol. 80.

[17] S. Beebe, "Eye Contact: A Nonverbal Determinant of Speaker Credibility," Speech Teach., vol. 23, 2009. 